\title{
Correction to: User Behaviour-Based Mobile Authentication System
}

\author{
Adnan Bin Amanat Ali, Vasaki Ponnusamy \\ and Anbuselvan Sangodiah
}

Correction to:

Chapter "User Behaviour-Based Mobile Authentication System" in: S. K. Bhatia et al. (eds.), Advances in Computer

Communication and Computational Sciences, Advances in Intelligent Systems and Computing 924, https://doi.org/10.1007/978-981-13-6861-5_40

The original version of the book was inadvertently published with the co-author's name as "Vasaki Ponnusamay", which has been now corrected as "Vasaki Ponnusamy" in Chapter 40. The erratum chapter and the book have been updated with the changes. 